\title{
JUDÍOS, INDIOS Y EL MITO DEL CRIMEN RITUAL. El Caso de Chamula, Chiapas, 1868
}

\author{
Jews, Indians and the Myth of Ritual Crime: The Case of Chamula, Chiapas, 1868
}

\author{
Misgav Har-Peled
}

Resumen: Entre 1867 y 1869 se vivió en Los Altos de Chiapas la rebelión de los indios chamulas contra los "ladinos" (mestizos) de San Cristóbal de Las Casas, conocida como Guerra de Castas. Según la historia oficial, los indígenas fueron acusados de crucificar el Viernes Santo de 1868 a un niño de dicha comunidad tsotsil. Este hecho puede compararse con la "leyenda de sangre" imputada secularmente a los judíos. En ambos casos un niño es sacrificado: crimen ritual que constituye una imitación de la Pasión de Cristo en la que, además, se utiliza la sangre derramada. La asociación de la leyenda de sangre contra los judíos y su transferencia a los indios suscita preguntarse si se trata de un suceso aislado, o si responde a una lógica más extensa que vincula al indio "salvaje" con el judío como el "asesino" del Hijo de Dios.

Palabras clave: Guerra de Castas (Chiapas), judíos, crimen ritual, Santo Niño de la Guardia.

Abstract: Between 1867 and 1869 in the Chiapas Highlands of Mexico, indigenous people of the Tsotsil Mayan municipality of Chamula rebelled against the mixed-blood "ladinos" of the town of San Cristobal de Las Casas. According to "official history", the indigenous people were accused of crucifying a child from Chamula on Holy Friday, 1868. This accusation may be compared with the "blood libel," which was blamed on the Jews. In both cases, a child was said to be sacrificed through a ritual crime imitating the Passion of Christ, in which the spilled blood was consumed. The transference of the blood libel against the Jews to the indigenous people of Mexico begs us to ask whether the latter event as an isolated occurrence or a response to a more elaborate system of thought linking the "savage Indian" with the Jew, assassin of the Son of God.

Keywords: Caste War (Chiapas), Jews, Blood libel, Holy Child of La Guardia.

Misgav Har-Peled, doctor en historia por la Universidad John Hopkins, Estados Unidos. Profesor-investigador en el Centre Edgar Morin, París, Francia. Temas de especialización: historia del fin de la antigüedad y de la Edad Media. Correo electrónico: misgavh@gmail.com.
Enviado a dictamen: 13 de mayo de 2014.

Aprobación: 04 de julio de 2014.

Revisiones: 1. 
E lestado de Chiapas se encuentra en el sureste de México, en la frontera con Guatemala. ${ }^{1}$ Como en la mayor parte de las colonias de España, en la época colonial no existió en la región población judía, pero el judío sí figuró en el imaginario colectivo por influencia del catolicismo. Como otras categorías de pensamiento, la imagen del judío puede ayudarnos a entender mejor las mentalidades o visiones del mundo de diversos grupos étnicos de Chiapas desde la época colonial hasta el presente. En particular, el judío puede convertirse en una categoría de alteridad que tercia y a la vez explica la ideología que ladinos e indígenas crearon respectivamente y por oposición mutua.

En el presente artículo profundizaremos en dicha construcción histórica enfocándonos en un caso de crimen ritual atribuido a los indios de Los Altos de Chiapas a fines del siglo XIX.

\section{San Juan Chamula, Chiapas: la Guerra de Castas (1868)}

En Chiapas se conoce como Guerra de Castas a la sublevación indígena que de 1867 a 1871 confrontó a los indígenas chamulas - de la etnia maya-tsotsil- contra los "ladinos" (mestizos) de Los Altos de Chiapas. El Viernes Santo de 1868, según cuenta la historia oficialtradicional, el líder indígena Pedro Díaz Cuscat ordenó a sus compañeros chamulas crucificar a un niño de su comunidad. De acuerdo con esta versión, después del horrible crimen cometido, los indios, alentados por el deseo de tener un Cristo propio, pudieron matar indiscriminadamente a los ladinos concentrados principalmente en la antigua capital del estado de Chiapas, la "blanca" Ciudad Real — actual San Cristóbal de Las Casas-.

Vicente Pineda, un "hijo" de San Cristóbal, publicó en 1888 el libro Sublevaciones indígenas en Chiapas (Esponda, 2001). Tal fuente, escrita dos décadas después de los hechos, es la única que menciona la crucifixión:

En la iglesia de Santo Domingo de Ciudad Real [San Cristóbal de Las Casas] hay una imagen que llaman el "santo entierro de Cristo," a quien los indígenas del pueblo de Chamula tienen mucha devoción, visitándola en cuaresma y principalmente en Viernes Santo, trayéndole velas de cera, flores y hierbas odoríferas. En la cuaresma de 1868 se notó que repentinamente los indígenas habían dejado de venir à romería; muchos creyeron que esto dependía de que ellos estaban muy satisfechos con los dioses que se habían forjado a su manera; pero a poco se averiguó que Pedro Díaz Cuscat les había hecho ver, que no necesitaban adorar á imágenes que representaban á personas que no correspondan á su raza, teniendo las propias, tanto más cuanto que las que había en los templos eran fabricadas por los ladinos; que estos en tiempo antiguo habían electo uno de entre ellos para clavarlo en una cruz á quien llamaban el Señor; que la crucifixión la repetían todos los años en cuaresma, y que acercándose el día en que esto debía verificarse, proponía hacer igual cosa con un vecino del pueblo para tener así un señor propio á quien adorar, que tuviera una misma alma y una misma sangre que sus hijos. La proposición fue aceptada, y á continuación se eligió para ser crucificado en el próximo Viernes Santo del año de 1868 al joven indígena Domingo Gómez Checheb, de diez á once años de edad, vecino del pueblo de Chamula, hijo de Juan Gómez Checheb y de Manuela Pérez Jolcogtom.

La crucifixión de un hombre es cosa no vista por estas tierras, por lo mismo la noticia se extendió con celeridad por todos las rancherías, de donde salió un numeroso concurso á presenciar el sacrificio cruento. Llegado el día colocaron una cruz en la plaza de Tsajalhemel, lugar en que tenían sus reuniones, sacaron à la victima de la pagoda y entre varios la sujetaron à la cruz; ya bien ligada, dieron principio à su bárbara, atroz y criminal ejecución, clavándole piés y manos à un tiempo. La infeliz víctima daba con voz lastimera y conmovedora, los más dolorosos gritos, ahogados por la algarabía de aquellas furias infernales, ébrias de licor y de sangre: las llamadas santas recogían la sangre del crucificado, otras lo sahumaban, espirando al fin el joven Domingo entre los más punzantes dolores. Ignoramos qué hicieron los nuevos judios con el cuerpo y sangre del mártir del salvajismo, aunque 
no es nada extraño que se hayan bebido esta última (Pineda 1888, 78-78).

El texto de Pineda se convirtió en la versión oficial de la llamada Guerra de Castas. ${ }^{2}$ El entusiasmo que el pasaje inspiró entre algunos historiadores llegó a la literatura. Rosario Castellanos, la escritora chiapaneca más importante del siglo XX, inmortalizó la leyenda de la crucifixión en su novela Oficio de tinieblas, de 1962: ${ }^{3}$

La actividad se concentraba ahora alrededor de la Gran Cruz del Viernes Santo. [...] Por fin la Cruz fue despojada de sus coberturas y la madera, antigua, sólida, sin pulir, quedó expuesta a los ojos que presenciaban el rito. [...] Luego vinieron los sahumerios. Siete sahumerios. El pom se consumía en las brasas y se difundía en el aire haciendo surgir, en quienes lo respiraban, la evocación de los grandes bosques de coníferas, la altura y la soledad de la cordillera (Castellanos, 1962: 313).

La novela de Castellanos fue adaptada a su vez en 1979 por Archibaldo Burns para una película con el mismo título. La crucifixión de Chamula sirvió igualmente como inspiración a Carter Wilson (1972) y a otros novelistas de ciencia ficción, como Norwood (1988), Shiner (1989) y Sterling (1990). ${ }^{4}$ Ante su difusión, la crucifixión pudo ser aceptada como un hecho verídico, incluso por algunos antropólogos que trabajaron en Chamula. Ricardo Pozas, en su clásico de la antropología mexicana Chamula: un pueblo indioen Los Altos de Chiapas (1959), especuló sobre el origen prehispánico de la crucifixión. ${ }^{5}$

Jan Rus fue el primero en cuestionar desde 1979 la realidad histórica de la crucifixión indígena. ${ }^{6}$ Sobre el tema publicó un célebre artículo en inglés (1983) y posteriormente en español (1995). Para Rus, la crucifixión del niño se trata de un mito porque el hecho no se menciona en ningún texto de la época de la rebelión, ni siquiera en los discursos más racistas de los periódicos publicados entre 1868-1871. ${ }^{7}$ El autor sugiere así que la historia de la crucifixión fue inventada por Pineda para demostrar la necesidad de tener en
Los Altos una presencia ladina fuerte, opuesta a los intereses liberales que en 1882 cambiaron la ubicación de la capital de Chiapas de San Cristóbal de Las Casas a Tuxtla Gutiérrez, en las "tierras bajas". En efecto, Pineda, miembro del partido conservador en su natal San Cristóbal, argumentó que, puesto que en el tiempo de la rebelión los poderes estatales habían sido retirados de la ciudad, los indios aprovecharon este "aislamiento" y "desamparo" para sublevarse y amenazar la existencia toda de la población "blanca". ${ }^{8}$ Con Rus (1989), Ulrich Köhler (1999, 358-362; 2001, 194) también afirmó que las tradiciones orales entre indios y ladinos sobre la Guerra de Castas omiten la narración de la crucifixión, de ahí que ambos autores refieran este hecho sin una base real concreta.

Otros investigadores continuaron aceptando como verídica la crucifixión en Chamula al margen de las observaciones de Rus. Victoria Bricker, en El Cristo indígena, el rey nativo. El sustrato histórico de la mitología del ritual de los mayas (1981), se pregunta si la crucifixión pudo tratarse de un invento de Pineda y responde:

Yo no lo creo, aunque no existen documentos históricos en los que pueda basar mi posición. Pienso que una crucifixión real o un simple remedo tuvo lugar en Chamula, pues es la única comunidad indígena de los Altos de Chiapas en donde, en la actualidad, se venera durante la Semana Santa a una personificación de Jesucristo indígena en lugar de una imagen del Santo Sepulcro (Bricker, 1993: 241). ${ }^{9}$

En 1992 el historiador Prudencio Moscoso Pastrana, oriundo de San Cristóbal de Las Casas, repitió la escena en Rebeliones indígenas de Los Altos de Chiapas y omitió las críticas de desmitificación de la crucifixión. En un tono similar al de Pineda más de un siglo atrás, dijo:

Como es natural el pequeño se defendía tratando de liberarse de aquella espantosa muerte, pero fue conducido por la fuerza y entre varios indígenas lo colocaron sobre la cruz y, al mismo tiempo, lo clavaron de los pies y manos. Entre los espantosos alaridos que daba la víctima inocente se podían oír 
las escandalosas voces de la muchedumbre que, con la ebriedad del licor y un desnaturalizado e inhumano entusiasmo, presenciaba aquelespantoso cuadro. El papel de las pretendidas santas se redujo a recibir la sangre de la inocente criatura y se sabe que algunos indígenas bebieron de aquel líquido. Al mismo tiempo, los que estaban más cercanos al lugar del sacrificio quemaban abundante incienso durante la crucifixión (Moscoso, 1992: 90). ${ }^{10}$

Pineda debe ser leído a la luz de su ideología y objetivos políticos. Autores más recientes, como Andrés Aubry (1989a: 39-40), indicaron que, para Pineda, "el papel es [un] arma para salvar el honor de la antañona capital del Estado que fue su cuna". Sin embargo, cuando en el prólogo de su obra el controvertido Pineda expuso los motivos que lo llevaron a escribirla, mencionó como el principal de éstos su deseo de evitar una nueva rebelión. ${ }^{11}$

Las rebeliones en Chiapas, según el libro de Pineda, tenían su causa en la naturaleza de los indios. Como otros autores "ladinos" de su época —es decir, mestizos educados dentro de la tradición colonial española-, los indios sólo podían ser "sanguinarios y feroces" o "bárbaros"; especie de "hordas indisciplinadas" que estaban más cerca de las "bestias feroces" al necesitar "satisfacer sus instintos salvajes". Así describió Pineda una batalla contra los indios:

\section{[...] los gritos y silbos de los bárbaros; con el pavoroso estruendo de la pelea; con los lastimosos alaridos de los que dejaban la vida para nunca más volver, con el furor brutal del salvaje que, careciendo de toda clase de sentimientos de humanidad y piedad no guarda ninguna consideración al vencido; con el horrible espectáculo que presenta aquella guerra de exterminio en la que doquiera que caen los golpes del bárbaro llevan consigo la muerte, y en vista de aquel torrente de sangre [...] (Pineda, 1888: 98).}

Pese a todo, Pineda (1888: 72) no pensaba que lo que denominaba "barbarie" fuera del todo natural en el indio, de ahí que la guerra no se trataba en realidad del enfrentamiento de blancos contra indios, sino "del salvajismo contra la civilización". No obstante, la bárbara situación de los indios justificaba, según Pineda, el fuerte control que ejercían aquellos que, trabajando al lado de la civilización —y valiéndose del uso de lenguas indígenas-, intentaban redimir a los indios del salvajismo en que vivían. ${ }^{12}$ A pesar de estos propósitos, Pineda no pudo ocultar su profundo racismo contra los indios. La descripción de la crucifixión es uno de sus mejores ejemplos porque muestra los "actos de fanatismo y superstición” indígenas. Al respecto, Rus (1995: 174) hizo notar que: "El horror de este relato, que constituía una prueba 'objetiva' de la falta de civilización de los indios, servía en ese entonces para justificar su sometimiento al sistema vigente de trabajo y endeudamiento en las plantaciones".

La acusación de Pineda contra los indios, más que relatar un estado "real" de los indios, remite a un imaginario ladino que concierne por lo menos al propio autor. ¿Cómo explicar esta invención de Pineda? Bricker piensa que, aun si la descripción de Pineda no se tratara de una crucifixión real, sí pudo ser en efecto una imitación de la crucifixión de Cristo. ${ }^{13}$

\section{¿Origen colonial?}

Es claro que, para Pineda, la crucifixión de Chamula se trata de una imitación-inversión de la Pasión: los indios actúan la escena, pero ésta es una aberración, pues los indios transforman el misterio último del Hijo de Dios en el sacrificio real de un niño. Este estigma de sangre contra los indios chamulas recuerda otras acusaciones de crucifixiones de niños por parte de indios, como las que registró trescientos años atrás el obispo de Yucatán, Diego de Landa. En las investigaciones inquisitoriales de este religioso contra los mayas de la península de Yucatán consta la confesión de Pedro Huhul de Kanchunup, de fecha 17 de agosto de 1562, en la que se menciona la crucifixión de dos niños:

[...] se hizo otro sacrificio a los ídolos en el cementerio de la iglesia delante de una cruz grande que allí estaba. Alrededor de ella tenían sus ídolos. 
Y que en el dicho sacrificio mataron y crucificaron dos muchachos que se decían Ah Chable y Ah Xol. El uno de los cuales que se decía Ah Chable lo crucificaron y enclavaron en una cruz grande que hicieron para el efecto, y que vivo lo pusieron en la cruz y le clavaron las manos con dos clavos y le ataron los pies abajo con un cordel. Y que los que clavaron y crucificaron el dicho muchacho fueron los ah-kines difuntos, lo cual fué hecho con consentimiento de todos los que allí estaban. Y después de crucificado alzaron la cruz en alto y el dicho muchacho daba voces, y así lo tuvieron en alto, y después lo bajaron en la cruz puesto le sacaron el corazón. Y que asimismo mataron el otro muchacho que allí estaba (Scholes y Adams, 1938: 94). ${ }^{14}$

Otra confesión, la de Antonio Pech, de fecha 19 agosto de 1562, reporta que en el pueblo de Sotuta se crucificaron dos niñas a demanda de los indios porque "mu[ri] eran estas muchachas puestas en la cruz como murió Jesucristo, el cual dicen que era Nuestro Señor, mas no sabemos nosotros si lo era" (Clendinnen, 2003: 78). Sobre estas descripciones, Inga Clendinnen refiere que se tratan más de un reflejo de la imaginación de los inquisidores españoles, que de una constatación fiable de los ritos mayas. ${ }^{15} \mathrm{El}$ proceso que intentó convertir a los mayas de Yucatán en "monstruos familiares", si usamos el término de Clendinnen, puede encontrar una explicación en la tendencia a creer en el origen judío de losindios, afirmación que el mismo Landa deja asentada en su Relación de las cosas de Yucatán..$^{16}$ Del mismo modo, Diego Durán, en el primer capítulo de su Historia de las indias de Nueva España (15761581), escribe sobre el origen de los indios: “[...] podríamos últimadamente afirmar ser naturalmente judíos y gente hebrea [...] sus ceremonias, sus ritos y supersticiones, sus agüeros e hipocresías, tan emparentados y propias a las de los judíos, que ninguna cosa difieren" (Durán, 1990:1). Para Durán, los sacrificios humanos prueban especialmente este origen judío:

[...] se consideran los ritos, las idolatrías y supersticiones que tenían: el ir a sacrificar a los montes, debajo de los árboles sombríos, a las cuevas y cavernas de la tierra oscuras y sombrías: el encender y quemar incienso, el matar sus hijos e hijas y sacrificarlos y ofrecerlos por víctimas a sus dioses; sacrificar niños, comer carne humana, matar los presos y cautivos en la guerra. Toda ceremonia judaica de aquellas diez tribus de Israel dichas; todo hecho con las mayores ceremonias y supersticiones que se puede pensar. Y lo que más me fuerza a creer que estos indios son de línea hebrea es la extraña pertinencia que tienen en no desarraigar de sí estas idolatrías y supersticiones [...] (Durán, 1990: 1).

Si los indios son de origen judío, ${ }^{17}$ en consecuencia deben ser los sacrificios que éstos realicen. Así el indio, como el judío, por su incapacidad de comprender el sentido espiritual, toma al pie de la letra lo sucedido en el sacrificio último de Cristo, el Hijo de Dios. Juan Ginés de Sepúlveda, en su Demócrates Segundo o de las justas causas de la guerra contra los indios (1547), anota que donde "las almas sanas y piadosas de los hombres" podían sacrificar metafóricamente un corazón, los indios procedían inconscientemente en sentido literal. ${ }^{18}$ Los indios, junto a los judíos, son imaginados cometiendo crímenes rituales, es decir, sacrificando niños en imitación de la pasión de Cristo. Por la misma razón, no extraña que Pineda (1888: 77-78) escriba al final del pasaje de la crucifixión que "ignoramos qué hicieron los nuevos judíos con el cuerpo y sangre del mártir del salvajismo, aunque no es nada extraño que se hayan bebido esta última". Para entender mejor esta asociación debemos remontarnos a otra leyenda de sangre y crucifixión, la más famosa de España: el mito del martirio del Santo Niño de La Guardia.

\section{El mito del martirio del Santo Niño de La Guardia}

En La Guardia, pequeña ciudad de la provincia española de Toledo, algunos judíos conversos fueron procesados por conspiración durante la Pascua judía de 1490. Se les acusó de haber pretendido robar una hostia para mezclarla con el corazón de un niño cristiano y hacer con ello una mágica comunión que pudo haber acabado 
con todos los cristianos al infectarlos de rabia. Si bien nunca se reportó la desaparición de un niño ni se encontró evidencia alguna, los inculpados por tan horrible crimen fueron quemados en la hoguera el 16 de junio de 1491, un año antes de la expulsión de los judíos de España (Shepard, 1991; Haliczer, 1991). El notario de La Guardia en 1544, el licenciado Damián de Vegas, fue el primero en narrar este hecho. En esta primera versión, titulada Memoria muy verdadera de la pasión y martirio, que el glorioso mártir, inocente niño, llamado Cristóbal..., puede leerse que los judíos crucificaron al niño en imitación de la Pasión de Cristo (Haliczer, 1991):

Finalmente quellos allí metidos, llevando allá al niño bendito, comenzaron á representar sus autos por el tenor y mejor forma que pudieron, como si otra vez crucificaran á ihesuchristo, haziendo todas las cerimonias, preguntas, acusaciones, blasfemias, bofetadas, repelones, escupir de cara, palabras feas y sucias, diziendo: Muerael traidor, que se quiso hazer Dios! muera el encantador ó burlador, que se hace rey de los judíos! [...] Después de bien açotado con unos manojos de aulagas llenas de espinas, y haziendo todo lo demás que pudieron, lo qual, por evitar prolixidad no escribo, cruzificaron al sancto niño en una cruz; la qual cruz diz que era de un exe de un carro; y estando enclavado en la cruz, le habrieron el costado derecho para sacarle el corazón; y como metiese la mano un judío de estos, llamado benito garcía de las mesuras ya dicho, no lo pudo hallar, y dixo: Dime, niño, adónde tienes el coraçon? Respondió el niño: Aquíle tengo, enel otro lado. Y así le tornó á abrir el otro costado, y lo sacó el coraçón y púsole en un plato; el qual plato tenía un judío destos, que se dezia mosén franco; el qual lo recibió en el dicho plato del dicho garcía de las mesuras; el qual para le sacar, después de le aver abierto el costado, tenía el cuchillo en la boca; el qual era sin punta y de una haz y como retomado; y en estos medios dió la ánima el sancto niño inocente á nuestro señor; con el qual goza de la gloria y gozará para siempre jamás (Fita, 1887: 140-141).
La narración de Vegas sirvió de base para elaborar la historia canónica del Santo Niño de La Guardia, que fue retomada a partir de 1572 en numerosas obras literarias. Entre ellas pueden nombrarse las siguientes: Seis libros sobre el secuestro del inocente mártir de La Guardia (De raptu innocentis martyris Guardienis), poema en latín de 1592 escrito por el maestro de Cervantes, Jerónimo Ramírez (1781: 21-26); El niño inocente de La Guardia, ${ }^{19}$ obra teatral que hacia 1603 escribiera el famoso dramaturgo español Lope de Vega, ola escrita en el siglo XVIII por el dramaturgo José de Cañizares. De hecho, aún hoy existe el culto al Santo Niño de La Guardia, presunta víctima del ritual criminal judío, y la ciudad de La Guardia lo venera como santo patrón en torno al cual se realiza cada año la fiesta local (Shepard, 1968).

En 1866 - dos años antes del presunto sacrificio del niño chamula-, Martín Martínez Moreno publicó en Madrid su Historia del martirio del Santo Niño de la Guardia, en la que describió la extracción del corazón del niño en la cruz. ${ }^{20}$ El libro presenta una imagen de la escena (ver figura 1), inspirada posiblemente en el cuadro sobre este tema de Francisco Bayeu (+1795) que se encuentra en la catedral de Toledo. Por otra parte, en la figura 2 podemos ver que uno de los judíos está sobre una escalera, con un cuchillo en los dientes, entregando el corazón del niño a su compañero. El hecho de que uno de los judíos se represente semidesnudo y con el cabello revuelto puede tomarse como una referencia a la barbarie o al salvajismo.

¿Cabe preguntarse si en el cuadro de Francisco Bayeu son representados tanto el judío sanguinario como el indio sacrificador de corazones? En efecto, algunos manuscritos de Lope de Vega sustituyen en El niño inocente de La Guardia (c. 1603) la palabra "iudio" por la de "indio" (Beusterien, 2006: 79). ${ }^{21}$ La sustitución de "judío" por "indio" no es un caso aislado en los textos coloniales españoles, pues efectivamente pueden confundirse los prefijos "ju" e "in" de ambas palabras. Sin embargo, en un sentido más profundo se percibe la proximidad entre dos categorías de alteridad (Elkin, 1993: 80; Malkiel y Malkiel, 1964; Boyarin, 2009: 39). Antonio de la Calancha (1638: 39) relató en 1638 una curiosa historia 
sobre alguien que alegó que una prueba del origen judío de los indios apareció en las palabras "Indio" y "Iudio": si uno invierte la "n" en la palabra "Indio", ésta cambia para decir "Iudio". ${ }^{22}$

\section{El eterno regreso}

Volviendo al caso de Chiapas, Pineda transfirió el mito del crimen ritual de una categoría étnica a otra. Si los indios son de origen judío o "nuevos judíos", entonces adquieren la característica más importante que a éstos otorga el imaginario cristiano: los judíos son los asesinos de Cristo. ${ }^{23}$ Así, los indios, como los judíos, se convierten en asesinos de Cristo y, por extensión, en "asesinos de niños". ${ }^{24}$ Frank Graziano (1999: 59) ofrece el ejemplo de 1751 en la frontera norte de Nueva España, cuando un colonizador justificó la paliza que daba a su esclava india diciendo esto: "Dios me ha dado vida para que pueda hacer a estos judíos lo que ellos hicieron a Nuestro Sacratísimo Señor" (Gutiérrez, 1993: 248). Otro ejemplo que menciona Graziano ocurrió en los Andes a finales del siglo XVIII, cuando el cura y doctor Ildefonso José de Mina indicaba la posible causa de la rebelión indigna de Túpac Amaru II:

Es muy común, y una de las mas fundadas opiniones q. ${ }^{e}$ estos Naturales descienden de los Hebreos, como se puede ver en la celebre obra del padre Garcia Dominicano, cuyo titulo es: Origen de los indios: ${ }^{25}$ en

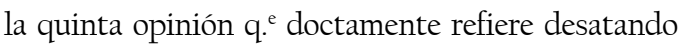
todas las dificultades $q$. ${ }^{e}$ se pueden ofrecer en contra de ella. Alli haze un paralelo muy circunstanciado de las costumbres de estos con las de aquellos, la imitación de sus usos, modos y aun expresiones de su idioma, descendiendo ultimamente y con prolijidad a la fuerza, ingratitud, brutalidad, e idolatria q. ${ }^{\text {e }}$ en aquellos infelices se vieron, y nos consta del sagrado texto (De Mina 1957, 724). ${ }^{26}$

Es en este orden de ideas como podemos situar la comparación que hace Pineda de los indios con "nuevos judíos". Bajo este epíteto, y considerando las acciones descritas en la crucifixión del niño Domingo Gómez
Checheb, en 1868, se justifica la opresión a los indios tal y como debieran merecerla los criminales judíos. ${ }^{27}$ En el mito de la Pasión de Cristo no cabe duda del rol negativo del judío: los judíos asesinaron al Hijo de Dios. En el mito de la leyenda de sangre o crimen ritual, el judío repite este crimen primordial matando un niño cristiano. Los colonizadores y misioneros trasladaron el mito de la Pasión del Mundo Antiguo al Nuevo Mundo. Como apunta Nash, la escena de la Pasión fue el drama más importante en las representaciones utilizadas por los misioneros españoles al introducir el catolicismo a los indios, pues ésta "contenía lo esencial de la ideología católica” (Nash, 1968: 318). La interpretación ladina de lo anterior en ocasiones adjudicaba al indio el papel del asesino judío de Dios. Al deshumanizar al "otro" - ya sea judío o indio-, la leyenda de sangre contribuye a unificar una sociedad determinada. ${ }^{28}$ El judío-indio o el indio-judío se transformó en el imaginario católico-colonial en un monstruo de inversión del cristianismo, siendo una de sus formas religiosas la perversa imitación-aversión de la religión verdadera. Antonio García de León (1985: 84) indica que "Aquí, el colonizado tampoco ponía en entredicho la legitimidad de la existencia del sistema; sólo promovía su inversión, como la imagen en una cámara oscura. Si los ladinos y españoles dominaban al indio en nombre de sus 'idolatrías' y origen hebraico [...], éste debía ahora invertir los papeles y dominarlos en nombre de un reino propio". ${ }^{29}$ La lógica que coloca a los indios como una simple "imagen de cámara oscura" no es india, sino ladina. En el imaginario colonial, el "otro" —indio o judío — sólo es "figura de pensamiento," sin existencia propia y, por lo mismo, sin identidad (Nelson, 1997: 336). El judío/indio del mito colonial consiste en una imagen "en negativo" del ladino bueno y católico. Así, el texto de Pineda, como el mito del Niño de La Guardia, califica la crucifixión del niño como una imitación mal hecha de la Pasión de Cristo; burda y bárbara incomprensión del cristianismo. En ambas narrativas el "otro" sólo existe como salvaje para devolver al cristiano, como en un espejo deformado, su propia imagen como el buen modelo. 
Si bien la comparación de los indios como judíos contribuye a su propia deshumanización, los indios chamulas tampoco rechazan la noción del judío como figura de mal..$^{30}$ Por el contrario, los indios se valen de ello e invierten los roles para acusar a su vez a los ladinos de judíos. Así, las escenas de carnaval o de la Pasión anteriormente mencionadas representan a los ladinos cometiendo tales actos: "iNo son entonces indios quienes matan a Cristo, sino que éstos tan sólo personifican a ladinos, los verdaderos criminales!' (Nash, 1968). Según Bricker (1993: 305), la costumbre del carnaval preserva la memoria de la crucifixión de 1868, pues a partir de entonces se "indigenizó" el concepto de la Pasión: si Jesucristo se transformó en indio, entonces "ladino" equivaldría a "judío". Esta afirmación de Bricker no tendría sentido en caso de que la crucifixión de 1868 fuera una pura invención de Pineda. El juego de la pasión en Chamula no confirma, como piensa Bricker, la teoría de Wallache (1956: 267), quien dice que "acaso los mitos, las leyendas y los ritos son reliquias o vestigios [...] de las doctrinas y la historia de cultos importados de revitalización, las circunstancias de cuyo origen se han tergiversado y olvidado". Al menos no como piensa Bricker: el ritual en Chamula no repite el evento de la crucifixión del niño, sino que invierte la leyenda de sangre de Pineda al decir que los judíos son ladinos en vez de indios. En el carnaval de Chamula el "judío" es simultáneamente un mono y un ladino; en particular, los soldados que aplastaron las rebeliones de 1712, de 18671890 y la de 1911, coincidente con la Revolución mexicana (Bricker, 1993: 130). Estas representaciones muestran la flexibilidad que puede brindarse a las categorías de alteridad en una configuración mítica: el indio se transforma en judío, el judío en indio y el ladino en judío.

\section{Conclusión}

La Guerra de Castas en Chiapas (1867-1871) ha sido un tema recurrente en la historiografía de este estado mexicano. He intentado aportar elementos que expliquen el posible origen de la crucifixión de un niño indígena, así como sus interpretaciones en el imaginario colectivo y entre los investigadores. Como la leyenda de sangre contra los judíos, la leyenda de sangre adjudicada a los indios continúa hasta la actualidad. ${ }^{31}$ Este mito pasó al gran público gracias a la novela de Castellanos Oficio de tinieblas, a la que siguió la adaptación de Archibaldo Burns al cine (1979). Aunque Castellanos —autora de corriente indigenista - considera que la rebelión indígena fue una reacción a la opresión ladina, por otro lado reproduce algunas de las calumnias de Pineda sobre los indios, incluido el pasaje de la crucifixión. Como ella misma comenta en una carta personal:
No son más que datos indispensables para formarse una idea de los acontecimientos, pero la impresión que queda es que las rebeliones podían reducirse a un arrebato dionisíaco, una orgía de sangre, una embriaguez colectiva de violencia que no quería ir más allá, que no tenía ningún plan posterior, y que desaparecido el primer ímpetu no se aprovechaba de las ventajas logradas (O'Connell, 1995: 141).

David MacDonald indica que las leyendas "sobre los sacrificios aztecas y el canibalismo son poco más que las versiones norteamericanas sobre el mito del 'crimen ritual judío'. Unos y otro deben ser tratados con escepticismo en vez de sincera auto-congratulación" (2008: 79). Lo mismo vale para el sacrificio del niño chamula, en 1868, o para los sacrificios mayas en general. En este contexto podemos pensar hoy en día en el imaginario sanguinario que Mel Gibson recrea tanto en su última película sobre los mayas, Apocalypto (2006), como en la que previamente realizó sobre los judíos en la Pasión de Cristo (2004). Al ser ambas películas repeticiones modernas de un viejo fenómeno - el binomio indio-judío-, cabe preguntarse si seguimos viviendo el peligroso eterno retorno de un mito sanguinario.

\section{Notas}

${ }^{1}$ Mis agradecimientos a Jérôme Baschet, Luz del Rocío Bermúdez, Justus Fenner, Antonio García Espada, Gerardo Liebner, Gilles Polin, David Nirenberg, Rocío Noemí Martínez, Rosa Luz Pérez, Jan y Diana Rus, Juan 
Pedro Viqueira, y a los anónimos lectores de la revista por sus sugerencias. All errors are mine.

${ }^{2}$ Según Ulrich Köhler (1999: 358-359), son doce los autores que mencionan la crucifixión: "Starr (1902: 68), Pozas (1959: 20), Köhler (1969: 109), Vogt (1969: 149), Favre (1971: 275), Gossen (1974: 2; 1977: 250, 252), Bricker (1979: 35; 1981: 122), Gow (1979: 54), Manguen y Montesinos (1979: 90), García de León (1985, I: 93), Moscoso Pastrana (1992: 90f) y Nelson (1997)". Los autores que aprueban la historia de la crucifixion son: Bricker (1979: 35-36), Gossen (1977: 273; 1999: 168), Gow (1979: 54) Favre (1973: 275), Colby y Van den Berghe (1961: 784), García de León (1985: 94), Nash (1968: 320), Starr (1904) y Vogt (1969: 149)".

${ }^{3}$ Ver la crítica de Jean Franco (1989: 14l) sobre la utilización romántica de la leyenda de la crucifixión.

${ }^{4}$ Sobre estos trabajos, ver Nelson (1997: 352, nota 35).

5 "La crucifixión de un joven tiene cierta relación con las antiguas prácticas de sacrificios humanos, aunque los antiguos mayas no sacrificaban tantas víctimas como los antiguos mexicanos. En tiempos de grandes necesidades publicas como sequías, huracanes, o las temidas plagas de langosta, los primeros sacrificaban en especial victimas humanas, con el fin de obtener lluvias generales" (Pozas, 1977: 40).

${ }^{6}$ XLIII Congreso Internacional de Americanistas, Vancouver, Canadá, agosto de 1979. Según Jan Rus, en la presentación de 1979 estuvieron presentes, entre otros, Ulrich Köhler, Jan de Vos, Nancy Farriss, Robert Wasserstrom, Kevin Gosner y Murdo MacLeod (comunicación personal, abril de 2012).

${ }^{7}$ Prudencio Moscoso Pastrana resolvió el problema imaginando que "Aunque parezca increíble, la cruel tragedia del niño victimado no se supo de inmediato en San Cristóbal ni en otros lugares, pues los indígenas que concurrieron a Tzajalemel guardaron el más profundo secreto" (1992: 91).

${ }^{8}$ Ver también Aubry (1989: 39).

${ }^{9}$ Bricker opina sobre la descripción de Pineda que "Las rebeliones indígenas de Chiapas, Guatemala, y la Península de Yucatán constituyen ejemplos de lo que Anthony Wallache ha denominado 'movimientos de revitalización’: es decir esfuerzos deliberados, organizados y conscientes por parte de los miembros de una sociedad para construir una cultura más satisfactoria. Los esfuerzos mayas por revitalizar su cultura por lo general han tomado una de las dos siguientes formas: 1) un intento por reinterpretar (i.e. 'revitalizar') los símbolos del mundo católico que les impusieron sus conquistadores españoles, con el objeto de transformarlos en algo más acorde con la experiencia indígena. 2) un intento por sacudirse lo que ellos consideraban era el yugo de la dominación 'extrajera' y por establecer su propio gobierno basado en el modelo español. En dos de los movimientos que habremos de analizar aquí, la reinterpretación tomó la forma de 'indigenización' del concepto de la Pasión de Jesucristo" (1993: 25-26).

${ }^{10}$ Sobre la historia de este libro, ver Esponda (1994). Sobre la vida de Prudencio Moscoso Pastrana, ver Homenaje al Profesor Prudencio Moscoso Pastrana, 1913-1991, Universidad Nacional Autónoma de México, Centro de Investigaciones Humanísticas de Mesoamérica y el Estado de Chiapas, México, 1994.

"1 "Las barbaridades de la guerra de castas, que, cual béstia feroz, no distingue sexo, edad, ni condición en las personas, y que para satisfacer sus instintos salbajes, el bárbaro destruye é incendia cuanto encuentra á su paso, sorprendiendo y asesinando en las altas horas de la noche á moradores inofensivos, nos impone el deber de dar á conocer á nuestros conciudadanos los principales hechos de armas habidos en las cuatro sublevaciones; las atrocidades y todo lo que pueda evitarles nuevas sorpresas para lo sucesivo" (Pineda, 1888: 16).

${ }^{12}$ Con este propósito Pineda anexó a su obra un diccionario español-tseltal.

${ }^{13}$ Robert Sitler, quien va en la misma dirección, propone que lo que puede achacarse a Pineda es la exageración, pues el acto en sí aún puede constatarse en la celebración de Semana Santa en Chamula, en donde el hombre que juega el rol de Cristo tiene clavos reales en sus manos, como describe Pozas: "It is unlikely that Pineda simply invented his account. Instead, it is an exaggeration and distortion of actual Chamulan Holy Week celebrations which include a vivid reenactment of Christ's crucifixion (Pozas, 181-91). From the anthropologist 
Ricardo Pozas' description of these events, it appears that the man chosen to play the role of Jesus may occasionally have real nails driven through his hands. Such practices, however, are more suggestive of intense devotional states or shamanic prowess than Chamulan barbarity" (Sitler, 1995: 352). Pero Pozas Arciniega no describe eso, sino una imagen de Cristo que los chamulas clavan sobre una cruz: "Detrás de la cruz, dos hombres subieron, uno por cada escalera, y esperaron al Cristo para crucificarlo. Los hombres que subieron a las escaleras ordenaron a la gente que volviera a hincarse. Cubriéndolo con el palio rectangular, subieron al Cristo a la cruz; lo sujetaron con unas fajas, le pusieron los clavos y, sin quitarle las fajas, se bajaron los dos hombres que crucificaron a Cristo" (Pozas, 1977: 189).

14 "Procesos contra los indios idólatras de Sotuta, Kanchunup, Mopila, Sabcaba, Yaxcaba, Usil y Tibolon. Agosto de 1562. Archivo General de las Indias, Escribanía de Cámara 1009B".

15 "Spaniard read the [Maya] rituals as deliberate blasphemies and parodies, but they do not conform to the sequence of Christ's crucifixion at all [...] the bulk of the later 'crucifixion' confessions were - as the Indian insisted - inventions, exacted by torments inflicted by the friars, just as the 'human sacrifice' accounts as given in the testimonies were not only multiplied but distortions, transformed in their meaning by being forced into a vocabulary the friars could recognize. The confessional texts as we have them rarely present descriptions of actual events. They are rather the product of the miserable confusion which besets men when they do not understand the speech of others, and find it easier to make of them familiar monsters than to acknowledge them to be different" (Clendinnen, 2003: 188).

16 “[...] algunos viejos de Yucatán dicen haber oído a sus (ante) pasados que pobló aquella tierra cierta gente que entró por levante, a la cual había Dios librado abriéndoles doce caminos por el mar, lo cual, si fuese verdad, era necesario que viniesen (de) judíos todos los de las Indias, porque pasado el estrecho de Magallanes se habían de ir extendiendo más de dos mil leguas de tierra que hoy gobierna España" (De Landa, 2001: 17).
${ }^{17}$ Sobre la teoría del origen judío de los indios, ver Méchoulan (1979), Huddleston (1967) y Gliozzi (1977).

18 “[...] para mí la mayor prueba que no descubre la rudeza, barbarie e innata servidumbre de aquellas gentes, son precisamente sus instituciones públicas, y que casi todas son serviles y bárbaras. Pues el hecho de tener casas y algún modo racional de vida en común y el comercio a que induce la necesidad natural, iqué prueba sino que ellos no son osos o monos carentes por completo de razón? Me he referido a las costumbres y carácter de los bárbaros, ¿qué diré ahora de la impía religión y nefandos sacrificios de tales gentes, que al venerar como Dios al demonio no creían aplacarle con mejores sacrificios que ofreciéndole corazones humanos? Y aunque esto último está muy bien, si por corazones entendemos las almas sanas y piadosas de los hombres, ellos, no obstante, referían esa expresión no al espíritu que vivifica (para usar de las palabras de San Pablo), sino a la letra que mata, y dándola una interpretación necia y bárbara, pensaban que debían sacrificar víctimas humanas y abriendo los pechos humanos arrancaban los corazones, los ofrecían en las nefandas aras y creían haber hecho así un sacrificio ritual con el que habían aplacado a sus dioses, y ellos mismos se alimentaban con las carnes de las víctimas. Crímenes son estos que al sobrepasar toda humana maldad son considerados por los filósofos entre las más feroces y abominables perversidades. Y en cuanto al hecho de que algunas naciones, según se dice, carecen por completo de religión y de conocimiento de Dios, iqué otra cosa es esto sino negar la existencia de Dios y vivir como las bestias? A mi juicio, este es el crimen más grave, torpe y ajeno a la naturaleza humana. El género de idolatría más vergonzoso es el de aquellos que veneran como Dios al vientre y a los órganos más torpes del cuerpo, que tienen por religión y virtud a los placeres del cuerpo, y que como los puercos siempre tienen su vista dirigida a la tierra, como si nunca hubiesen mirado al cielo. A éstos, sobre todo, se les aplica aquel dicho de San Pablo: cuyo fin es la muerte, cuyo dios es el vientre, pues tienen sabor a cosas terrenas". líneas 916-945 (Ginés de Sepúlveda, 1951: 37-38).

${ }^{19}$ Ver Lope de Vega (1985) y Morrison (2000). Sobre la datación de esta última obra, ver De Cañigral Cortés (1994: 369). 
20 "Mas biendo el Santo Inocente que el sacrílego judío andaba buscando el corazón revolviendo las entrañas con su mano carnicera, y no lo hallaba, le preguntó: ¿Qué buscas, judío? Si buscas el corazón, yerras buscándolo en esa parte; búscalo al otro lado y lo encontrarás. Así lo ejecutó el malvado, hirióle en el otro costado, y le sacó prontamente el corazón. iAh bárbara fiereza! iah verdugo cruel é inhumano!" (Martínez Moreno, 1866: 67-68).

${ }^{21}$ Como nota Beusterien, la inversión ortográfica judío-indio tiene su paralelo en algunos textos en inglés de la época. En una línea del acto $\mathrm{V}$, escena 2, en el manuscrito de la obra Otthello de Shakespeare, la lectura varía entre "Indian" y "Judean" (Holmer, 1980; Levin, 1982; Barthelemy, 1994: 99). ${ }^{22}$ Citado por Huddleston (1967: 85). Para otros ejemplos de América Latina, ver Elkin (1993: 80-81).

${ }^{23}$ Sobre el mito del judío como asesino de Cristo, ver Cohen (2007).

${ }^{24}$ Frank Graziano (1999: 59) apunta: "Role identities and their values are kept in circulation, with one or another privileged to suit a particular occasion. In the sixteenth and seventeenth centuries the Indians were fashioned as descendants of the lost tribes of Israel to suit the demands of orthodoxy and noble savagery, but by the eighteenth century the regard for these recycled Israelites was overhauled in response to rebellion".

${ }^{25}$ Ver García, fray Gregorio (1729).

${ }^{26}$ Ver la discusión de Graziano (1999: 59).

${ }^{27}$ Otro ejemplo sobre la justificación de la opresión a los indios, tal y como debieran merecerla los criminales judíos, es la comparación que realizan algunos autores coloniales entre la toma de México por los españoles (1521) y la del este de Jerusalén por los romanos (70 d.C.) (Lupher, 2003).

${ }^{28}$ Como nota Diane M. Nelson sobre la imaginaria crucifixión de Chamula: "Only by negating this barbaric, crucifying "other" could those claiming the extremely complex category of ladino experience a unified (if fleeting) identity" (Nelson, 1997: 348).

${ }^{29}$ Citado por Nelson (1997: 336).

${ }^{30} \mathrm{El}$ antropólogo Gary H. Gossen nota en su libro sobre Chamula: "[...] I realized one day in silence and was afraid to admit or discuss: I shared a homeland and a national identity with millions of Jews and black people who, in league with the ancient monkeys, were thought explicitly responsible for the death of the Sun/ Christ deity, as reported in story after story of the First Creation. Indeed, my very being and "co-being" seemed to bear moral qualities that were reprehensible to the Chamula Tzotzils - they very people whom I wished to understand and celebrate" (Gossen, 1999: 14).

31 Bricker escribe que "Actualmente, los tratos de Chamula con los indios son mínimos, ya que no hace mucho los indígenas de esta comunidad arrojaron a la población ladina residente y el año pasado ahuyentaron del Municipio al sacerdote ladino; los Chamulas tienen la reputación de ser peligrosos y de tomar rápidamente sus cuchillos, machetes o rifles a la menor provocación. El potencial de rebeldía está siempre presente en las tierras altas, aún hoy día, ya que los indígenas superan en número a los ladinos, pero son tratados como inferiores por ellos" (Bricker, 1973: 328-329).

\section{Referencias bibliográficas}

Aubry, Andrés (1989), Gente de Chiapas, San Cristóbal de Las Casas. Chiapas, Instituto de Asesoría Antropológica para la Región Maya.

Barthelemy, Anthony Gerard (1994), "Ethiops Washed White: Moors of the Nonvilanious Typr". En Barthelemey, Anthony Gerard (ed.), Critical Essays on Shakespeare's Othello. Nueva York, G.K. Hall, pp. 91-103. Beusterien, John (2006), An Eye on Race: Perspectives form Theater in Imperial Spain. Lewisburg, Bucknell University Press.

Boyarin, Jonathan (2009), The Unconverted Self: Jews, Indians and the Identity of Christian Europe. Chicago, Chicago University Press.

Bricker, Victoria Reifler (1973), "Algunas consecuencias religiosas y sociales del nativismo maya del siglo XIX”. En América Indígena, vol. 33, núm. 2, pp. 327-348.

Bricker, Victoria Reifler (1979), "Movimientos religiosos indígenas en Los Altos de Chiapas". En América Indígena, vol. 39, núm. 1, pp. 17-46.

Bricker, Victoria Reifler (1981), The Indian Christ, the Indian King: the Historical Substrate of Maya Myth and Ritual. Austin, University of Texas Press. 
Bricker, Victoria Reifler (1993), El Cristo indígena, el rey nativo. El sustrato histórico de la mitología del ritual de los mayas. México, Fondo de Cultura Económica.

Castellanos, Rosario (1962), Oficio de tinieblas. México, J. Mortiz.

Clendinnen, Inga (2003), Ambivalent Conquests: Maya and Spaniard in Yucatan, 1517-1570. Nueva York, Cambridge University Press.

Cohen, Jeremy (2007), Christ Killers: the Jews and the Passion from the Bible to the Big Screen. Oxford/ Nueva York, Oxford University Press.

Colby Benjamin y Pierre van den Berghe (1961), "Ethnic relations in southeastern Mexico". En American Anthropologist, vol. 63, núm. 5, pp. 772-92.

De Cañigral Cortés, Luis (1994), "El niño inocente de La Guardia de Lope de Vega, Análisis de sus fuentes". En Revista de Literatura, vol. 46, núm. 112, pp. 349-70.

De la Calancha, Antonio (1638), Crónica moralizada del orden de San Agustín en el Perú con sucesos ejemplares en esta monarquía. Barcelona, Pedro Lacavallería.

De Landa, Diego. Fray (2001), Relación de las cosas de Yucatán. Itzimna. México, Dante.

Durán, Diego, Fray (1990), Historia de las indias de Nueva España e islas de la tierra firme. Madrid, Banco Santander.

Elkin, Judith (1993), "Imagining Idolatry: Indians, Missionaries, and Jews". En Siebers, Tobin (ed.), Religion and the Authority of the Past. Ann Arbor, University of Michigan Press, pp. 75-93.

Esponda Jimeno, Víctor Manuel (1994), "La rebelión tzotzil de 1869". En Homenaje al profesor Prudencio MoscosoPastrana(1913-1991). San Cristóbal de Las Casas, Chiapas, Centro de Investigaciones Humanísticas de Mesoamérica y el Estado de Chiapas, Universidad Nacional Autónoma de México, pp. 75-79.

Esponda Jimeno, Víctor Manuel (2001), “Vicente Pineda Espinosa, historiador y lingüista”. En Tertulia, núm. 2, pp. 23-29.

Favre, Henri (1971), Changement et continuité chez les Mayas du Mexique: contribution à l'étude de la situation coloniale en Amérique latine. París, Anthropos.

Fita, Fidel (1887), "Memoria del Santo Niño de la Guardia, escrita en 1544”. En Boletín de la Real Academia de la Historia, vol. 11, pp. 135-160.
Franco, Jean (1989), Plotting Woman: Gender and Representation in Mexico. Nueva York, Columbia University Press.

García, fray Gregorio (1729), Origen de los indios de el Nuevo Mundo e Indias Occidentales. Madrid, Francisco Martínez Abad.

García de León, Antonio (1985), Resistencia y utopía: memorial de agravios y crónica de revueltas y profecías acaecidas en la provincia de Chiapas durante los últimos quinientos años de su historia, t. l. México, Era.

Ginés de Sepúlveda, Juan (1951), Democrates Segundo o de las justas causas de la guerra contra los indios. En Losada, Ángel (ed.). Madrid, Instituto Francisco de Vitoria.

Gliozzi, Giuliano (1977), Adamo e il nuevo mondo: La nasita dell'anthroplogia come ideologia colonale: Dalle genalogie boliche alle teorie razziali (1500-1700). Florencia, Nuoba Italia, pp. 49-110.

Gossen, Gary H. (1977), "Translating Cuzcat's War: Understanding Maya Oral Tradition”. En Journal of Latin American Lore, vol. 3/2, pp. 249-278.

Gossen, Gary H. (1999), Telling Maya Tales: Tzotzil Identities in Modern Mexico. Nueva York/Londres, Routledge.

Gow, David D. (1979), "Símbolo y protesta: movimientos redentores en Chiapas y en los Andes peruanos". En América Indígena, vol. 39, núm. 1, pp. 47-80.

Graziano, Frank (1999), The Millennial New World. Nueva York, Oxford University Press.

Gutiérrez, Ramón A. (1993), Cuando Jesús llegó, las madres del maíz se fueron: matrimonio, sexualidad y poder en Nuevo México, 1500-1846. México, Fondo de Cultura Económica.

Haliczer, Stepen (1991), "The Jews as Witch: Displaced Aggression and the Myth of the Santo Niño de la Guardia”. En Pary Mary, Elizabeth y Anne J. Cruz, Cultural Encounters. The Impact of the Inquisition in Spain and the New World. Berkeley/Los Angeles/Oxford, University of California Press, pp. 146-156.

Holmer, John Ozark (1980), "Othello Threnos: 'Arabian Trees' and 'Indian' versus 'Judean”. En Shakespeare Studies, vol. 13, pp. 145-167.

Huddleston, Lee Eldridge (1967), Origins of the American Indians; European Concepts, 1492-1729. Austin, Institute of Latin American Studies, University of Texas Press. 
Köhler, Ulrich (1999), Der Chamula-Aufstand in Chiapas, Mexiko: Aus der Sicht heutiger Indianer und Ladinos, Münster, Lit Verlag, pp. 358-359.

Köhler, Ulrich (2001), "The Chamula-Revolt of 1869: New Insight from Oral and Written Sources". En Hostettler, Ueli y Matthew Restall (eds.), Maya Survivalism, Acta Mesoamericana, vol. 12, pp. 191-200.

Levin, Richard (1982), "The Indian/Judean Crux in Othello”. En Shakespeare Quarterly, vol. 33, pp. 60-67.

Lewin, Boleslao (1957), La rebelión de Túpac Amaru y los orígenes de la emancipación americana. Buenos Aires, Librería Hachette.

Lope de Vega y Carpio, Félix Arturo (1985), El Niño Inocente de la Guardia: A Critical and Annotated Edition, with an Introductory Study by Anthony J. Farrell. Londres, Tamessi.

Lupher, David M. (2003), Romans in a New World: Classical Models in Sixteenth-Century Spanish America. Ann Arbor, University of Michigan Press.

MacDonald, David B. (2008), Identity Politics in the Age of Genocide: the Holocaust and Historical Representation. Londres/Nueva York, Routledge.

Malkiel Yakov y Malkiel, María Rosa (1964), "The Jews and the Indian: Traces of a Confusion in the Hispanic Tradition". En For Max Weinreich on his Seventieth Birthday: Studies in Jewish Languages, Literature, and Society. The Hague, Mouton, pp. 203-208.

Martínez Moreno, Martin (1866), Historia del martirio del Santo Niño de la Guardia. Madrid, Imprenta de Tejado, pp. 67-68.

Méchoulan, Henry (1979), Le sang de l'autre ou l'honneur de Dieu: Indiens, juifs, morisques dans l'Espagne du siècle d'or. París, Fayard, pp. 54-58.

Morrison, Robert R. (2000), "El niño inocente de La Guardia, comedia famosa". En Lope de Vega and the Comedia de Santos. Nueva York et al., Peter Lang, pp. 127-136.

Moscoso Pastrana, Prudencio (1992), Rebeliones indígenas en Los Altos de Chiapas. México, Universidad Nacional Autónoma de México, Centro de Investigaciones Humanísticas de Mesoamérica y del Estado de Chiapas.

Nash, June (1968), "The Passion Play in Maya Indian Communities". En Comparative Studies in Society and History, vol. 10, pp. 318-327.
Nelson, Bruce (1997), "Crucifixion Stories, the 1869 Caste War of Chiapas, and Negative Consciousness: A Disruptive Subaltern Study". En American Ethnologist, vol. 24, núm. 2, mayo, pp. 331-354.

Norwood, Warren C. (1988), True Jaguar. Nueva York, Bantam Books.

O'Connell, Joanna (1995), Prospero's Daughter: the Prose of Rosario Castellanos. Austin, University of Texas Press.

Pineda, Vicente (1888), Sublevaciones indígenas en Chiapas. Chiapas, Tipografía del Gobierno, pp. 77-78.

Pozas Arciniega, Ricardo (1977 [1959]), Chamula: un pueblo indio en Los Altos de Chiapas, t. I. México, Instituto Nacional Indigenista.

Ramírez, Jerónimo (1781), De raptu innocentis martyris Guardienis. En Cerdá y Rico, Francisco (ed.), Claroroum Hispanorum: Opuscuala Selecta et Rariora..., v. I. Madrid, Sacnha, pp. 1-94.

Romero de Castilla, Manuel (ed.) (1943), Comedias históricas: el niño inocente de Lope de Vega y La viva imagen de Cristo de José de Cañizares. Madrid, Hermanos de la Doctrina Cristiana.

Rus, Jan (1983), "Whose Caste War? Indians, Ladinos and the Chiapas 'Caste War' of 1869". En MacLeod, Murdo J. y Robert Wasserstrom, Spaniards and Indians in Southeastern Mesoamerica: Essays on the History of Ethnic Relations. Lincoln, University of Nebraska Press, pp. 127-168.

Rus, Jan (1989), "The 'Caste War' of 1869 from the Indians' Perspective: A Challenge for Ethnohistory". En Memorias del Segundo Coloquio Internacional de Mayistas, t. II. México, Centro de Estudios Mayas, UNAM, pp. 1033-47,

Rus, Jan (1995), “¿Guerra de castas según quién?: indios y ladinos en los sucesos de 1869". En Viqueira, Juan Pedro y Mario Humberto Ruz (eds.), Chiapas, los rumbos de otra historia. México, UNAM/CIESAS, pp. 145-174.

Rus, Jan (1996), "Whose Caste War? Indians, Ladinos and the Chiapas 'Caste War' of 1869". En Gosner, Kevin y Arij Ouweneel, Indigenous Revolts in Chiapas and the Andean Highlands. Amsterdam, The Netherlands, CEDLA, pp. 43-78 
Scholes, France V. y Eleanor B. Adams (1938), Don Diego Quijada, alcalde mayor de Yucatán, 1561-1565, t. I. México, Antigua Librería Robredo, de J. Porrúa e hijos.

Shepard, Sanford (1968), "The Present State of the Ritual Crime in Spain”. En Judaism, vol. 17, pp. 68-78.

Shepard, Sanford (1991), "The Present State of the Ritual Crime in Spain”. En The Blood Libel Legend. A Casebook in Anti-Semitic Folklore. Madison, University of Wisconsin Press, pp. 162-179.

Shiner, Lewis (1989), Deserted Cities of the Heart. Toronto, Bantam Books.

Sitler, Robert K. (1995, "Rosario Castellanos' Oficio de Tinieblas: The Maya Otherworld through Ladina
Eyes". En Selected Proceedings of the 16th CHISPA. Baton Rouge, Louisiana State UP, pp. 347-56.

Starr, Frederick (1904), "Notes Upon the Ethnography of Southern Mexico. Expedition of 1901". En Proceedings of the Davenport Academy of Sciences, t. IX, 1901-1903, pp. 63-171. Vogt, Evon Z. (1969), "Chiapas Highlands”. En Vogt, Evon Z. (ed.), Handbook of Middle American Indians, t. 7, Ethnology, Part One. Austin, University of Texas Press, pp. 133-15l.

Wallace, Anthony E.C. (1956), "Revitalization Movements: Some Theoretical Considerations for their Comparative Study". En American Anthropologist, vol. 58, pp. 264-281.

Wilson, Carter (1972), A Green Tree and a Dry Tree. Nueva York, MacMillan Company. 
Figura 1. Desde la cruz de su patíbulo consiguió del Señor dar vista á su madre ciega

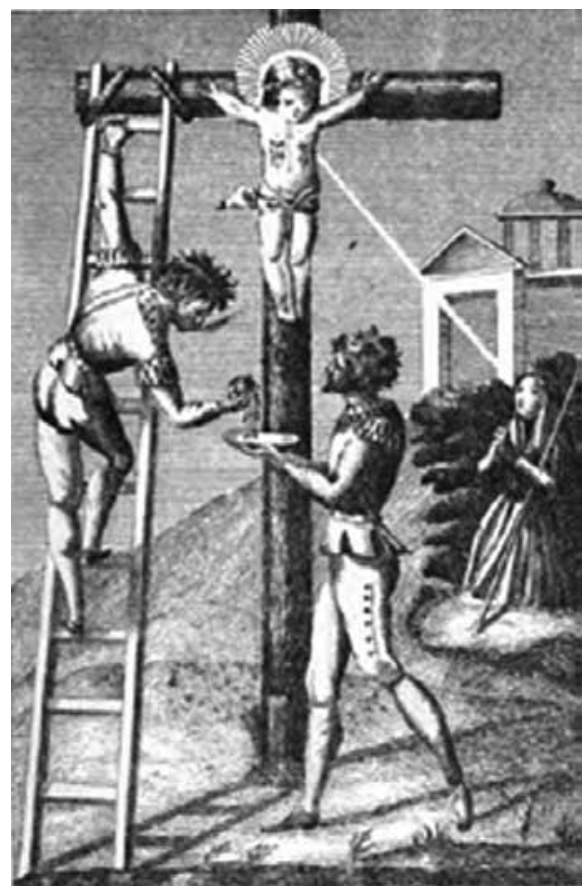

Fuente: Martínez Moreno, Historia del martirio del Santo Niño de la Guardia (1866: 116a).

Figura 2. La crucifixión de Santo Niño de La Guardia

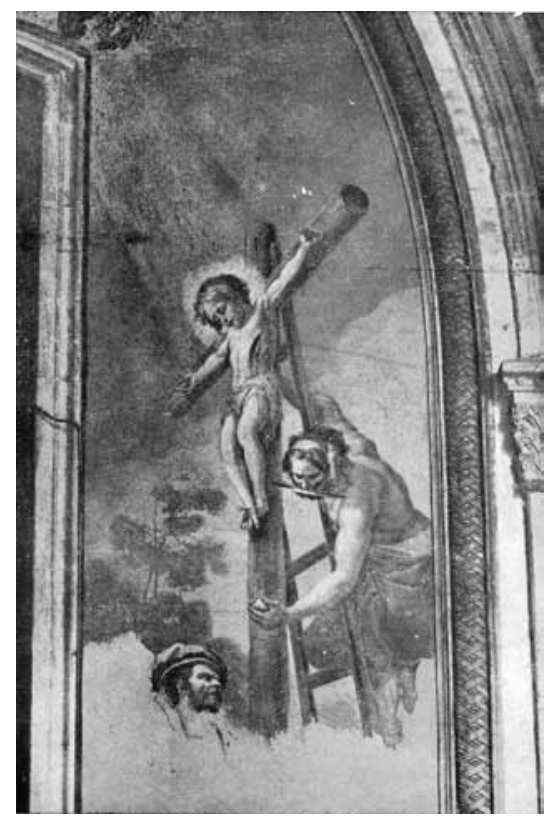

Fuente: Francisco Bayeu (1734-95). Catedral de Toledo, Puerta del Perdón (Romero de Castilla, 1943). 